\title{
Editorial \\ Surgical Techniques Development: A Multidisciplinary Medium for the Future Practical Surgery
}

Egidio Riggio

Citation: Riggio, E. Surgical

Techniques Development: A

Multidisciplinary Medium for the

Future Practical Surgery. Surg. Tech.

Dev. 2022, 11, 2-3. https://doi.org/

$10.3390 / \operatorname{std} 11010002$

Received: 31 January 2022

Accepted: 4 February 2022

Published: 9 February 2022

Publisher's Note: MDPI stays neutral with regard to jurisdictional claims in published maps and institutional affiliations.

Copyright: (C) 2022 by the author Licensee MDPI, Basel, Switzerland. This article is an open access article distributed under the terms and conditions of the Creative Commons Attribution (CC BY) license (https:// creativecommons.org/licenses/by/ $4.0 /)$.
Plastic Surgery Unit, Fondazione IRCCS Istituto Nazionale dei Tumori, 20133 Milan, Italy; Egidio.Riggio@istitutotumori.mi.it

Surgical Techniques Development is an Open Access peer-reviewed journal focusing on minimally invasive surgical techniques, technical innovations such as new instruments, new technologies, new robotics applications, and other new ideas, and is open to suggestions coming from all areas of surgery.

Within this era of exciting developments, I am delighted to continue my role of Editorin-Chief for Surgical Techniques Development, international scientific journal established in 2011 by PAGEPress (Pavia, Italy) and now, since 24 January 2022, published by MDPI (Basel, Switzerland). I recently succeeded Professor Mark G. Shrime, otolaryngologist surgeon from Harvard Medical School as Editor-in-Chief. MDPI is a pioneer in scholarly Open Access publishing and has supported academic communities since 1996.

Surgical Techniques Development is the first online-only journal reporting on the diffusion of the research for multidisciplinary innovation, as well intending to be the spotlight for different surgical specialties such as head and neck, endoscopy, gynaecology, thoracic surgery, cancer care and, due to my core curriculum, skin and breast cancer surgery together with the most modern aspects of plastic reconstructive and aesthetic surgery.

The journal has been indexed by ESCI (Web of Science), and we believe this will allow us to reach a larger audience, which will enhance the visibility and impact of research for the potential authors.

Surgeons who are the trendsetters of surgical progresses, and younger surgeons who want to keep up with the most up-to-date assessments and technologies in surgery, can from now on revert to Surgical Techniques Development as their dedicated journal. Progress in recent years has led surgical technologies and procedures to extend to several specialties, thus the need for a journal to collect all related topics.

MDPI will re-release Volume 11, Issue 1 in March 2022, and change its publication frequency to quarterly. We will be inclined to the rapid publication of various types of articles such as review articles, short communications, opinion papers, commentary, survey articles, single case studies and other manuscript types in the fields of surgical innovations. Additionally, videos illustrating surgical techniques are welcome.

Let us work together as authors and reviewers to prepare good papers for the journal that will be free to download, share, and reuse content. Authors will receive recognition for their contribution when the paper is reused and cited.

Conflicts of Interest: The author declares no conflict of interest. 
Short Biography of Authors

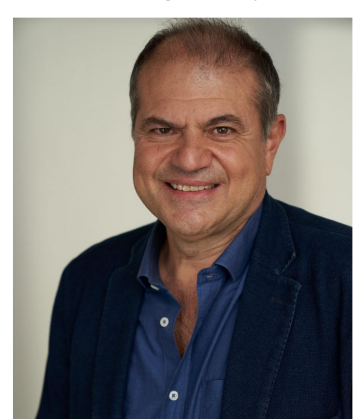

Dr. Egidio Riggio is Consultant of Plastic and Reconstructive Surgery in a tertiary cancer center in Milano, Fondazione IRCCS Istituto Nazionale dei Tumori, which is historically one of the leading hospitals in Europe and in the world for the cancer care. He received his MD in 1989 from University of Palermo and two specialty qualifications from the University of Milano, in Plastic Surgery in 1994 and in General Surgery (experimental and micro surgery) in 1997. After fellowships in Plastic surgery and Head and Neck surgery, he became engaged in education and research, and today is a consultant at the same cancer institute in Milano, with over 50 peer-reviewed publications and book chapters, and over 180 participations in courses and symposiums (over 50 as invited speaker or chairman). His scientific and surgical activities mainly focus on breast and facial surgery. Dr. Riggio currently is member of the Committee for the Improvement of Breast Units in the Sicilian Region, and is member-elect of the national Board of the Italian Association of Plastic and Aesthetic Surgeons. 